\title{
Copper-Catalyzed Stereospecific Allylic Alkylation of Ketene Silyl Acetals
}

Metal-Catalyzed

Asymmetric

Synthesis and

Stereoselective

Reactions

\section{Key words}

allylic alkylation

copper

regioselectivity

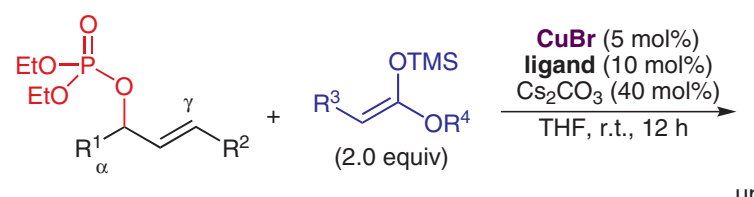

Selected examples:<smiles>C/C=C/[C@H](CCCC)[18O]CC</smiles><smiles>C/C=C\[C@H](CCCCC)[Pb]OCC</smiles>
$97 \%$ ee<smiles>CCO[18O]C(CC(=O)OCC)OCC</smiles>

Proposed reaction pathway:<smiles>[TeH]</smiles><smiles>[R]C=CC([R])C([R])C(=O)O</smiles>

up to $94 \%$ yield up to $99: 1$ regioselectivity $(\gamma / \alpha)$ up to $99: 1 \mathrm{E} / \mathrm{Z}$ up to $>99 \%$ chirality transfer

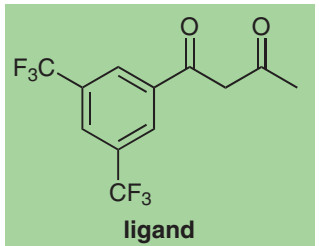

$82 \%$ yield $\gamma / \alpha=95: 5$ $E / Z>99: 1$ $96 \%$ ee

$85 \%$ yield $\gamma / \alpha=98: 2$ $E / Z>99: 1$ $96 \%$ ee<smiles>CCCC/C=C/C(C)CC(=O)OCC</smiles>

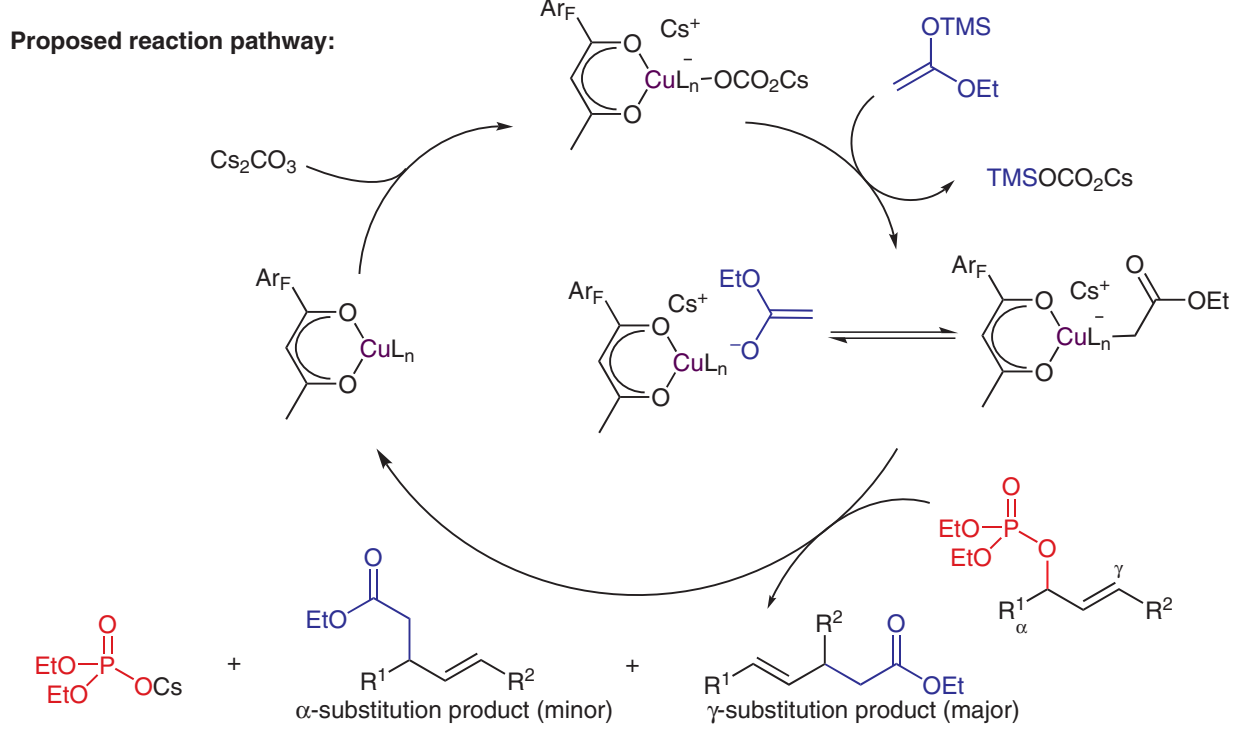

Significance: Allylic alkylation of enolates is an important transformation in organic synthesis. The copper-catalyzed method described employs unsymmetrical internal allylic phosphates as electrophiles, which react with excellent $\gamma$-regioselectivity and excellent $Z$-diastereoselectivity.

SYNFACTS Contributors: Hisashi Yamamoto, Patrick Brady Synfacts 2011, 7, 0737-0737 Published online: 17.06.2011 DOI: 10.1055/s-0030-1260653; Reg-No.: H06311SF
Comment: The $\gamma$-selective allylic alkylation of chiral allylic phosphates proceeds with efficient 1,3-anti $\alpha$-to- $\gamma$ chirality transfer. The stereochemical outcome of the product is dependent on the $E / Z$ geometry of the allylic phosphate. The authors propose the reaction pathway shown above, invoking an allyl copper(III) intermediate. 